\title{
Publishing scientific research in open access, hybrid, or paywall journals: what model serves all authors and all readers?
}

\author{
Kate Lajtha
}

Published online: 31 August 2019

(C) Springer Nature Switzerland AG 2019

There has been a great deal of discussion in the media as well as in scientific journals about open access publishing and Plan S, the movement to mandate that scientists funded by specific types of grants publish in fully open-access journals. To date, 16 funders in 13 countries have signed on to this plan, it has found support in the Bill \& Melinda Gates Foundation and other non-governmental funders, and that number will likely have gone up by the time this editorial is published. By 2021, Plan S funders will allow grantees to publish papers only on platforms that offer immediate open access; discussion are underway to address the APC that publishers can charge. Plan S has drawn support from many scientists, who are concerned over the current publishing system that generates large profits for corporations and that keeps taxpayerfunded research results behind paywalls. Certainly, the anger at high subscription prices of journals that can cripple University budgets is justified. Scientists have argued that the services that scientists provide to journals for free should not be used for profit by those not engaged in the scientific process.

As currently written, however, Plan S has received a great deal of criticism. An Open Letter was signed by more than 1800 researchers ranging from masters students to full professors and Nobel laureates, from

K. Lajtha $(\bowtie)$

Oregon State University, Corvallis, OR 97331, USA

e-mail: lajthak@science.oregonstate.edu both cOAlition $\mathrm{S}$ countries and non-cOalition countries, arguing against Plan S (https://sites.google.com/ view/plansopenletter/open-letter). These researchers specifically objected to the ban on hybrid journals, as many scientific societies rely on revenue from publication charges to fund their stated missions to members of their societies, such as funding student travel, hosting workshops, etc. Many have argued that Plan S's requirements will overwhelmingly affect the selective journals that many societies publish, as scientific societies that are looking to fund activities have a smaller economy of scale than large publishing houses (Brainard 2019). In these cases, hybrid journals do not direct profits to non-science shareholders or CEOs but rather back to their members. Marcia McNutt, president of the National Academy of Sciences and former editor-in-chief of Science as well as former president of AGU, offers very specific critiques of Plan S that do not need to be repeated here (McNutt 2019). She points out the merit in directing society publishing profits to enhance society programs that support students, underrepresented minorities, community engagement, and other worthy causes.

As the editor of a journal published by a for-profit publisher, Springer Nature, but also as a scientist with a need to publish papers and have those papers read, I see the merits and problems associated with both sides of the argument. I greatly benefit from the services that Springer Nature provides to me and to my editorial board: we have manuscript review software that has an 
editorial assistant who responds to my calls for help within hours if not minutes; my publisher offers advice, support, and guidance when the editorial board has questions or ideas; we have copy editors and printers and web managers that make my life easy and that help produce a top-notch international journal. Publishers have also been instrumental in helping create indexing and discovery tools, among other platforms used by the research community. As a fellow editor-in-chief of a journal, also from a forprofit publisher, is fond of saying, publication is not free, and good publication is not cheap. So the problem is not that there is a cost to the publication process, it is the profit margin and that profits are not returned to the scientific enterprise. As a University scientist, I know that my University is paying high subscription fees for the journals it carries, and this cost is carried by Oregon taxpayers. And yet, like many voices before me, I have grave concerns about Plan S that I believe are not guided by the fact that I work for Springer Nature in my role as an Editor (full disclosure). As outlined by Spedding et al. (2019), Plan S emphasizes the merits of open access but does not address the many problems that it will generate. Like most active scientists, I receive invitations from an average of 5-10 open access journals a day, none of which I have ever heard of. How will Plan $S$ address predatory publishers, how will scientific quality of journals be maintained, and what incentives will open access journals have for ever rejecting a paper? Readers of respected journals such as Biogeochemistry know that a well-vetted Associate Editor has picked authoritative reviewers, sifted through reviews, and decided to accept a paper because it has passed review and thinks it will be well cited. Knowing that there is no financial gain in accepting a paper makes our readers able to trust the quality of papers we publish.

Other concerns about Plan S are not as well discussed in the literature. I have spent significant time with colleagues in eastern Europe where University libraries are not well funded. For them, access to papers that they need for their research is not immediate. However, I argue that almost all papers are already virtually open access, and although my colleagues have to work harder and put more time into accessing papers, they do get almost all papers that they search for and request. Most journals that I read have a little email symbol by the first author's name; clicking on that generates an email, and I have never yet been turned down for a reprint. My colleagues in Hungary and Romania find this process tedious, but workable. However, they shudder at the thought of having to pay to publish, as do graduate students in fields that are not well supported by grants. Do I also need to worry about finding funds if a graduate student's research takes an unexpected turn, and they are able to produce an unexpected paper that is not in the direct line of the grant that funds them? I have a few Honors College students in my lab: do I need to worry about their research working out too well so that a terrific publication can be realized from their work? These are "what if" scenarios, but real concerns that can substantially limit student creativity.

No matter what publishing plan is in place, a paywall will continue to exist-right now the paywall is to read research, and it can be a relatively easily overcome paywall as long as authors are allowed to send reprints and post pre-prints. With Plan S, the paywall will be to publish, and that is not as easily overcome. So what can be done? I suggest that the global scientific research community can mobilize, given how flat the world is with respect to communication. Researchers can use the power of our numbers to come up with a plan that maximizes flexibility to authors and readers, and limits profits to non-scientific efforts. Some things that I believe can be negotiated:

1. Caps on library subscription costs and fees. Communities can organize and refuse to publish in journals with exorbitant profits and fees. Communities can also use the power of numbers to negotiate new pricing and publishing models with major publishers, following the lead of Projekt DEAL (https://www.projekt-deal.de/ about-deal/), a consortium of university libraries and research institutes in Germany, that just successfully negotiated a publishing partnership with Wiley. Several societies are already arguing for significant caps on author processing charges (Rabesandratana 2019).

2. Ways to generate read-only copies of articles that can be freely shared. Springer Nature's free content-sharing initiative SharedIt provides links to view-only, full-text subscription research articles that can be posted anywhere-including on social media platforms, author websites and in institutional repositories-so researchers can 
share research with colleagues and general audiences.

3. Mandates that all papers have (a) open Table of Contents with abstracts and (b) a small email logo that can be clicked to access the corresponding author's email; authors should be given access to products such as SharedIt to make sharing simple.

4. A time after which articles are truly open access. Several publishers, including Springer Nature and Taylor \& Francis, allow authors to archive earlier versions of their work and also encourage selfarchiving: an author's accepted manuscript can be made available on their own personal, selfmaintained website immediately on acceptance. This version can also be available for public release 12 months after first publication on their employer's internal website and/or funder repositories. Springer Nature is also currently working with organizations such as ResearchGate to facilitate the sharing of articles on other platforms.

I also argue that hybrid journals should be seen as more than just a pathway to fully open-access publishing. Hybrid means that researchers who are required to publish open access papers can do so, while also allowing journals the flexibility to meet the needs for no-fee publishing from regions of the world and from students for whom the burden of open access would limit their right to publish. As stated in a post from the official blog of the Society for Scholarly Publishing, hybrid is a responsive model, because it can adjust to balance changing demand for open access publishing without forcing it on others (Hinchcliffe 2019).

Historians state the scientific publishing began in the mid 17th century, and has experienced several transformative revolutions such as using peer review and online publishing. We are certainly facing one of the greatest revolutions in publishing models now. Let's hope that whatever publishing model emerges from the revolution addresses the competing needs of all readers and all authors, as well as taxpayers, funders, and research institutions.

\section{References}

Brainard J (2019) Scientific societies worry about threat from plan S. Science 363:332-333

Hinchcliffe LA (2019) Is hybrid a valid pathway to open access? Publishers Argue Yes, in Response to Plan S. Retrieved from https://scholarlykitchen.sspnet.org/2019/02/19/ishybrid-valid-pathway-to-open/?utm_source=feedburner\& utm_medium=email\&utm_campaign=Feed $\% 3 \mathrm{~A}+$ Scholarly Kitchen+\%28The+Scholarly+Kitchen $\% 29$

McNutt M (2019) Opinion: "Plan S" falls short for society publishers-and for the researchers they serve. Proc Natl Acad Sci USA 116:2400-2403

Rabesandratana T (2019) The world debates open-access mandates. Science 363:11-12

Spedding M, Barrett J, Morgan ET, Vore M, Geraghty D, Kirkpatrick C, Cascorbi I (2019) Plan S: a threat to quality of science? Science 363:462

Publisher's Note Springer Nature remains neutral with regard to jurisdictional claims in published maps and institutional affiliations. 